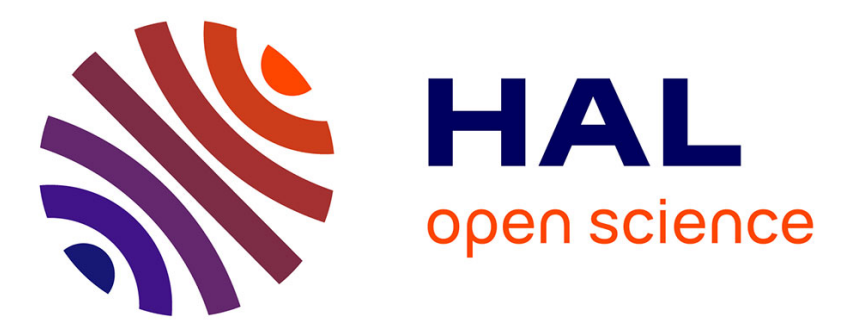

\title{
Occupational solvent exposure during pregnancy and child behaviour at age 2 .
}

Fabienne Pelé, Gina Muckle, Nathalie Costet, Ronan Garlantézec, Christine Monfort, Luc Multigner, Florence Rouget, Sylvaine Cordier

\section{- To cite this version:}

Fabienne Pelé, Gina Muckle, Nathalie Costet, Ronan Garlantézec, Christine Monfort, et al.. Occupational solvent exposure during pregnancy and child behaviour at age 2.. Occupational and Environmental Medicine, 2013, 70 (2), pp.114-9. 10.1136/oemed-2012-100892 . inserm-00795043

\section{HAL Id: inserm-00795043 https://www.hal.inserm.fr/inserm-00795043}

Submitted on 1 May 2013

HAL is a multi-disciplinary open access archive for the deposit and dissemination of scientific research documents, whether they are published or not. The documents may come from teaching and research institutions in France or abroad, or from public or private research centers.
L'archive ouverte pluridisciplinaire HAL, est destinée au dépôt et à la diffusion de documents scientifiques de niveau recherche, publiés ou non, émanant des établissements d'enseignement et de recherche français ou étrangers, des laboratoires publics ou privés. 


\title{
Occupational Solvent Exposure During Pregnancy and Child Behavior at Age Two
}

Correspondence to

Fabienne Pelé, INSERM IRSET U1085; Université Rennes I, Campus de Beaulieu, 35042

Rennes, France;

fabienne.pele@univ-rennes1.fr

Tel : +0033 (0) 223236126

Fax : +0033 (0) 223235055

Fabienne Pelé, ${ }^{\mathrm{a}, \mathrm{b}}$ Gina Muckle, ${ }^{\mathrm{c}, \mathrm{d}}$ Nathalie Costet, ${ }^{\mathrm{a}}$ Ronan Garlantézec, ${ }^{\mathrm{a}, \mathrm{e}}$ Christine Monfort, ${ }^{\mathrm{a}}$ Luc Multigner, ${ }^{\mathrm{a}}$ Florence Rouget, ${ }^{\mathrm{a}, \mathrm{f}}$ Sylvaine Cordier ${ }^{\mathrm{a}}$

a - INSERM IRSET U1085; Team of Epidemiological Research on Environment,

Reproduction and Development ; University of Rennes I, Rennes, France

b - University Hospital Rennes, Epidemiological and Public Health Service, F-35033 Rennes,

France

c - CHUQ Medical Research Center, Québec City, Québec, Canada

d - School of Psychology, Laval University, Québec City, Québec, Canada

e - University Hospital Brest, Public Health Service, Brest, France

f - University Hospital Rennes, Pediatric Department, F-35033 Rennes, Rennes, France

KEY WORDS:

occupational health, solvents, child behavior, neurodevelopment, prenatal exposure

WORD COUNT: 3320

\begin{abstract}
Objectives: Many women who work during pregnancy are occupationally exposed to toxicants. The developing central nervous system is highly vulnerable to neurotoxics such as solvents. Although the neurotoxicity of solvents to adults is well established, very few studies have examined their effects on children's behavior following prenatal exposure.

Methods: Women from the PELAGIE mother-child cohort (including 3005 working women) were recruited in Brittany (France) between 2002 and 2006, at the beginning of pregnancy, to assess occupational exposure to solvents at that time. Child behavior was documented at age two by mothers $(\mathrm{n}=1278)$ assessing components of attention deficit/hyperactivity, aggression, opposition, and emotionality. We used a multiple linear regression analysis to evaluate the association between occupational solvent exposure and children's behavior. Complementary sensitivity analyses allowed us to handle missing data, due mostly to attrition.

Results: $20 \%$ of women reported occasional exposure and $31 \%$ regular exposure to solvents. Children prenatally exposed were more likely to have higher scores of attention deficit/hyperactivity and aggression, and dose-response relations were observed.

Conclusion: The dose-response effect and the high prevalence of children potentially exposed to solvents from their mother's workplace exposure underline the public health relevance of this result. Our results should be replicated in further studies designed to identify which solvents are most deleterious and to assess child behavior at school age.
\end{abstract}




\section{WHAT THIS PAPER ADDS}

- Animal experiments have reported both behavioral changes and neurochemical modifications in rats after prenatal exposure to solvents at concentrations that produced no observable maternal toxicity.

- The neurotoxicity of solvents to adult humans is well known, but effects on child behavior following prenatal exposure are understudied.

- The results of this prospective cohort study, the largest thus far conducted of the developmental effects of prenatal solvent exposure, indicate that solvent exposure early in gestation may be related to non-optimal child behavior at age two. 


\section{INTRODUCTION}

Solvents are ubiquitous in industrialized societies as a component of numerous products. Occupational exposure may occur during the manufacture of plastics, drugs, pharmaceutical products, and essential oils, and during the manufacture or use of such widely used products as paints, inks, glues, varnishes, dyes, cosmetics, detergents and cleaning agents, and grease removers. Acute poisoning cases have demonstrated their neurotoxic properties, and occupational studies among adults chronically exposed to low to moderate doses have further corroborated these. ${ }^{1}$

Solvents belong to three main chemical families: oxygenated, petroleum, and chlorinated. All three can cross the placenta and the fetal blood-brain barrier. ${ }^{2,3}$ The human brain develops mostly during the intrauterine period, that is a period with high susceptibility to neurotoxicants. ${ }^{3,4,5}$ Studies of laboratory animals have reported both behavioral changes (affecting learning capacity and exploratory activity) and neurochemical modifications in rat offspring after prenatal exposure to, for example, glycol ethers, at concentrations that produced no observable maternal toxicity. ${ }^{6,7,8}$

Given the high number of women potentially exposed to solvents during their pregnancy in industrialized countries and the association between solvent exposure, neurodevelopment, and behavior in animal studies, even small effects on childhood behavior due to prenatal solvent exposure might have substantial public health effects. Thus far, only three other studies have assessed the association between prenatal occupational solvent exposure and child behavior, and two of them reported significant associations. In 1988, Eskenazi et $\mathrm{al}^{9}$ prospectively followed 92 children up to 3.5 years and failed to find an association between solvent exposure and child behavior. The small sample size and the low level of exposure were presented as likely explanations for the absence of significant associations. In 2001, Till et al ${ }^{10}$ conducted a prospective cohort study in which children aged 3 to 7 years of 33 pregnant occupationally exposed women (mostly laboratory workers/technician, factory workers/machine operators, and graphic designers) were compared to the children of 28 unexposed women. Externalized and internalized behaviors were documented from maternal report by the Child Behavior Checklist (CBCL). More than $60 \%$ of the exposed women reported clinical symptoms related to their solvent exposure (headache, visual irritations, or nausea). After adjustment for most confounders, exposed children had higher rates of internalizing and externalizing behaviors. Laslo-Baker et $\mathrm{al}^{11}$ corroborated these results in 2004 by comparing 32 exposed children ( 3 to 9 years old) with 32 unexposed children according to maternal reports of their child's behavior. Occupationally exposed mothers were mostly laboratory technicians, factory workers, and graphic designers. Exposed children had higher global scores on the Conner's Rating Scale-Revised, the CBCL, and the Behavioral Style Questionnaire, higher internalizing and externalizing scores on the CBCL, and higher hyperactivity/impulsivity and hyperactivity scores on the Conner's Rating Scale-Revised.

The objective of the present study was to determine, through a large-scale epidemiological study, if early exposure to solvents during pregnancy in occupationally exposed women is associated with nonoptimal behavior during early childhood. The study design allowed us to adjust for multiple factors known to affect child behavior.

\section{METHODS AND MATERIALS}

\section{Participants}

The PELAGIE mother-child cohort study, described elsewhere, ${ }^{12,}{ }^{13}$ included 3421 pregnant women recruited before 19 weeks of gestation in three districts of Brittany (France), between 2002 and 2006. The analyses here are restricted to women who reported working at 
the beginning of pregnancy and gave birth to a liveborn singleton $(n=2938)$. We sent a questionnaire to 2638 eligible mothers around the children's second birthday, excluding families where the child $(n=4)$ or mother $(n=1)$ had died and those where the children were older than 2.5 years on the date we first sent the questionnaire $(n=295)$. Of the 2638 eligible mothers, 668 never received the questionnaire because of wrong or no longer valid mailing addresses (that is, the post office returned the questionnaires to us). Among the remaining 1970 mothers, who presumably received the questionnaire, 1359 (69\%) mailed it back completed. Solvent exposure status was known for 1291 women in this group. Two children with a disorder that could cause behavioral problems were excluded (trisomy 21, severe cranial trauma), and we restricted analyses to mother-child pairs for whom at least one of the four child behavior scores could be computed ( $\mathrm{n}=11$ excluded). The final study sample included 1278 mother-child pairs. Mothers provided informed written consent, and the appropriate ethics committees approved the study procedures.

\section{Assessment of solvent exposure}

At inclusion, in early pregnancy, women were asked to report the frequency of their current occupational contact (never, occasional or regular) with 11 classes of products known to contain solvents: paints, strippers, varnishes, dyes, inks, glues, gasoline, grease removers, detergents and cleaning agents, textile treatment agents, and cosmetics. We classified subjects as not exposed if they reported no exposure to any of these products, occasionally exposed if they reported occasional exposure to at least one product, and regularly exposed if they reported regular exposure to at least one product.

This exposure characterization was validated by a biomonitoring study performed on a randomly selected sample $(n=451)$ of the 3421 women included in the PELAGIE cohort ${ }^{14}$. This study examined, among other things, the urine levels of 8 metabolites of glycol ethers (GE; family of oxygenated solvents) and two metabolites of chlorinated solvents (trichloroethanol (TCOH) and trichloroacetic acid (TCAA)), according to the women's selfreported assessment of solvent exposure. Of the 379 women reporting working at the beginning of pregnancy, 370 reported their occupational contact to solvents at work; $19 \%$ reported occasional exposure and 29\% regular exposure. Three (ethoxyacetic acid, EAA; ethoxy ethoxyacetic acid, EEAA; 2-butoxyacetic acid, BAA) of the 8 GE metabolites and $\mathrm{TCOH}$ were found significantly more frequently in the urine of women who reported regular occupational exposure compared with unexposed women. The rates of detection of those metabolites increased with the category of indirectly assessed solvent exposure (occasional, regular). More specifically, correlations were established between the presence of some metabolites and the use of products containing solvents such as cleaning agents (associated with EAA, EEAA, BAA, TCAA and TCOH in the urine), cosmetics (with EAA, EEAA, BAA, and phenoxyacetic acid), and paints and strippers (EEAA).

\section{Assessment of child behavior}

At the 2-year follow-up, the child's principal caregiver, usually the mother (98\%), completed an instrument composed of 15 questions designed to assess the child's behavior at age two. This instrument was developed for the Quebec Longitudinal Study of Child Development (QLSCD). ${ }^{15,16}$ Questions were derived from the CBCL, ${ }^{17,} 18$ a widely used and validated scale, and from the Preschool Social Behavior Questionnaire. ${ }^{19}$ Numerous studies based on the QLSCD showed the stability and predictive validity of this instrument in which data was gathered in the caregiver's home. For example, hyperactivity-impulsivity scores were stable from 17 to 42 months ${ }^{20}$ and from 2 to 7 years. ${ }^{21}$ Scores were obtained from a 3point Likert scale of $5^{20}$ (can't sit still, is restless, or hyperactive; fidgets; cannot settle down 
to do anything for more than a few moments; is impulsive, acts without thinking; has difficulty waiting turn in games) or $3^{21}$ items (can't sit still, is restless, or hyperactive; cannot settle down to do anything for more than a few moments; has difficulty waiting turn in games). The Cronbach $\alpha$ reliability coefficients in these studies were 0.75 at 17 months, 0.75 at 30 months and 0.71 at 42 months for the 5-item scale and 0.80 for 24- to 35-month-old children for the 3-item scale. Aggression scores, obtained from a 3-point Likert scale of 3 items (got into fights; physically attacked others; hit, bit, kicked others), were also stable from 17 to 42 months, ${ }^{22}$ and opposition scores (was defiant or refused to comply with adults' requests or rules; didn't seem to feel guilty after misbehaving, punishment didn't change his/her behavior) were stable from 29 to 74 months. ${ }^{23}$ The internal consistency values were 0.55 at 17 months, 0.61 at 30 months and 0.76 at 42 months for the aggression scale and 0.54 , $0.60,0.63,0.64$ and 0.62 at $29,41,50,61$ and 74 months respectively for the opposition scale. The emotionality scale has shown adequate psychometric properties for the evaluation of emotional disorders in childhood. ${ }^{24}$

The questions used in the PELAGIE study assessed attention deficit/hyperactivity $(\mathrm{AD} / \mathrm{H})$, aggression, opposition, and emotionality. The respondents were asked to self-report the frequency of specific behaviors (Table 1) over the preceding three months on a 3-point Likert scale (never (0), sometimes (1), or often (2)). The AD/H score was computed as the sum of 6 items and ranged from 0 to 12. Scores of aggression, opposition and emotionality were each computed from the sum of 3 items and ranged from 0 to 6 . Thus each score represented $\mathrm{AD} / \mathrm{H}$, aggression, opposition and emotionality disorders as a continuous trait, ${ }^{25}$ and higher scores were indicative of greater manifestations of the targeted behavioral phenotype.

\section{Covariates and potential confounders}

At inclusion, we collected by self-report the following social, demographic, and lifestyle characteristics: age of mother at first delivery, single mother status, maternal education ( $\leq 12$ years, $>12$ years), smoking during the first trimester of pregnancy (nonsmoker, 1 to 5 cigarettes/day, $\geq 5$ cigarettes/day), and alcohol consumption at the beginning of pregnancy (no alcohol, $<1$ drink per day, $\geq 1$ drink per day). The medical report at birth included the child's sex, preterm birth ( $<37$ weeks of gestation), and status as smallfor-gestational age (SGA), defined by a birth weight below the fifth percentile of the birth weight distribution for gestational age and sex, according to French reference curves. ${ }^{26}$ Additional information collected at 2 years together with the behavior assessment questionnaire included: the child's age in months at follow-up, number of siblings at followup ( $0,1,2$ or more), breast feeding ( $\leq 3$ months, $>3$ months), and scores for mother-child interaction and father-child interaction. The latter two variables are the sum of responses to 5 questions: Do you sing with your child? Do you read stories or show pictures in a book to your child? Do you play with games at home with your child? Do you take your child for walks? Do you play physical games with your child? Coding for each item ranged from 1 to 5 (never or almost never, less than once a week, once or twice a week, 3 to 5 times a week, and every day or almost). Internal consistency was good: 0.75 for the mother-child interaction score and 0.77 for the father-child interaction score. An exploratory factorial analysis showed the unidimensionality of these scales.

\section{Statistical analyses}

Multivariate regression analyses were performed to determine the effect of occupational solvent exposure during pregnancy on each behavior score. Covariates known to affect child behavior were included in multivariate regression models. To test a dose-response 
effect, we used a test for trend after ensuring that the conditions of application were met. ${ }^{27}$ Models appropriate to the distribution (linear regression for normal distribution and Poisson regression for Poisson distribution) were used. The stability of the results was verified with sensitivity analyses involving multiple imputation and restriction. Multiple imputation ${ }^{28}$ is a technique in which the missing values are replaced by $m>1$ simulated versions. In this study, 10 data sets ${ }^{29}$ were generated, with observed values identical across the data sets, but various imputed values. Imputed values were estimated conditionally on other variables. We ran multivariate linear regression including the same covariates as above on each imputed data set. Then the results were combined to produce estimates and standard deviation that incorporated missing-data uncertainty. Restriction analysis was performed on a subgroup excluding women with any well-known risk factors for behavioral problems, i.e., smoking or alcohol use during pregnancy and low education. SAS software version 9.1 (SAS institute, Inc., Cary, NC) and R software version 2.10.1 were used for data analysis.

\section{RESULTS}

Compared with the 1278 participants, nonrespondents $(n=1358)$ were less educated $(\mathrm{p}<0.0001)$, younger at first delivery $(\mathrm{p}<0.0001)$, and more likely to smoke $(\mathrm{p}<0.0001)$, but similar for alcohol consumption, duration of gestation, SGA percentage, and occupational solvent exposure.

Table 2 presents the families' social and demographic characteristics and solvent exposure. More than two-thirds of the women had completed high school and almost all were living with a partner. About $25 \%$ had smoked at the beginning of pregnancy, and although about $15 \%$ drank alcohol while pregnant, very few reported more than one standard drink of alcohol daily. Most of the children were born at term, by vaginal delivery, with a normal birth weight for gestational age.

Twenty percent of the women reported occasional exposure to solvents at the beginning of pregnancy, and $31 \%$ regular exposure. Five occupations had the highest frequency (more than 50\%) of regular solvent exposure: nurses and related; nurses' aides; chemists, biologists and related; cleaners and helpers; and hairdressers and beauticians. In terms of type of exposure, of the women reporting regular exposure at work $(n=391), 70 \%$ (272/391) reported regular exposure to detergents and cleaning agents. Fifty percent of the women worked up to the $28^{\text {th }}$ week of gestation (interquartile range: $23-32$ ) and overall $6.5 \%$ changed jobs or tasks during pregnancy. Women who had production jobs had changed jobs most frequently (25\%). The women from the five occupations that explained most of the solvent exposure changed jobs at the average rate.

Good internal consistency was observed with Cronbach $\alpha$ of 0.73 for the AD/H score, 0.61 for the hyperactivity-impulsivity dimension, and 0.78 for the aggression score. Cronbach $\alpha$ values of 0.56 for opposition (better for children that were 29 month or more; 0.63 ) and 0.52 for emotionality were less satisfactory. Low to moderate intercorrelations were observed among behavioral indicators (Table 3). The $\mathrm{AD} / \mathrm{H}$ and opposition variables followed a normal distribution while aggression and emotionality scores were close to a Poisson distribution. Nevertheless, results with linear regressions are presented for each behavior variable because they were identical to those obtained with Poisson regressions.

Table 4 presents the mean behavioral scores at age two according to the level of solvent exposure during pregnancy. Results from multiple regression analyses for each score are presented in Table 5. The slope shaped by the mean scores of $\mathrm{AD} / \mathrm{H}$ and aggression at each level of exposure was statistically different from 0 and showed a steady increase in scores for each level of occupational exposure. When we looked at the differences according to levels of exposure, mean scores were almost all statistically different between the no- 
exposure and regular-exposure groups: p-values were 0.03 for $\mathrm{AD} / \mathrm{H}$ and 0.009 for aggression in the univariate analyses, and respectively 0.06 and 0.04 in the multivariate analyses. Mean scores were never statistically different between non-exposed and occasionally-exposed groups in either the univariate or multivariate analyses. Neither opposition nor emotionality scores were related to solvent exposure. The same results were obtained when multiple imputations were performed, under the missing at random assumption. The imputed sample included 2636 mother-child pairs. Two types of missing data were present in the data set: due to attrition $(n=1279)$ and missing values $(n=285$ for $A D / H, n=265$ for aggression, $n=264$ for opposition, $\mathrm{n}=254$ for emotionality multivariate analysis). Linear trends were confirmed for both $\mathrm{AD} / \mathrm{H}$ score $(\beta=0.13 \pm 0.07 ; \mathrm{p}$-trend $=0.08)$ and aggression score $(\beta=0.12 \pm 0.05 ; \mathrm{p}$ trend=0.03). When analyses were restricted to the subgroup of more highly educated women who reported not smoking and not drinking alcohol during pregnancy, the association between occupational solvent exposure and aggression remained significant $(n=713$, ptrend=0.07), but not the association with $\mathrm{AD} / \mathrm{H}(\mathrm{n}=696$, $\mathrm{p}$-value $=0.14)$.

\section{DISCUSSION}

Our results support the hypothesis that prenatal exposure to solvents through maternal occupational exposure is associated with greater behavioral manifestations of aggression and may be associated with greater behavioral manifestations of $\mathrm{AD} / \mathrm{H}$ during early childhood. Opposition and emotionality, as operationalized in this study, were not related to in utero solvent exposure. These results are consistent with two ${ }^{10,11}$ of the three previous studies, which were conducted with smaller samples, highly exposed groups and older children. Although those studies used different items to assess child behavior, they were conducted with the CBCL, the instrument from which our item sets were derived. They found more internalized and externalized disorders in exposed children and, with respect to externalized behaviors, ${ }^{11}$ higher levels of hyperactivity/impulsivity. Aggression, opposition and emotionality were not assessed previously.

This study is one of only a few epidemiological prospective cohort studies of the behavioral effects of prenatal solvent exposure, and it is the first on so large a scale. Furthermore, this study is unique with regard to its excellent statistical power in controlling for multiple factors known to be associated with child behavior. ${ }^{22,}{ }^{30-36}$ Other study strengths are the period of assessment of solvent exposure, during early pregnancy, a period known for its high susceptibility to developmental toxicants ${ }^{4}$ and its prospective longitudinal nature, which enabled exposure characterization long before maternal reports of child behavior. However, the exposure assessment presents some limitations, as we could not quantify the intensity of solvent exposure (for example, use of protective equipment was unknown). But this semi-quantitative exposure measurement was validated in a subset of the cohort. As pointed out above, five occupations had the highest frequency of regular solvent exposure $(>50 \%)$ in our cohort. The description of the classes of solvents present in these work environments $^{37-40}$ and the correlations observed between urinary biomarkers and products handled ${ }^{14}$ point to two groups of products (cleaning agents and cosmetics) and at least one chemical class of solvents (oxygenated solvents, comprising alcohols, ethers, ketones, and esters) as common to several of these work environments and likely to explain the classification as regularly exposed to solvents by indirect methods. To limit the number of questions for respondents and thus increase acceptability, we selected a questionnaire used in another French-speaking general-population cohort and sought to evaluate child behavior from maternal reports with optimal sensitivity and fewer questions. Several Canadian studies have shown the stability and predictive validity of this instrument. ${ }^{20-24,35} \mathrm{We}$ observed good internal consistency in our cohort for the $\mathrm{AD} / \mathrm{H}$ and aggression subscales, but less with the 
opposition and emotionality scores that were similar to the internal consistency observed in the QLSCD despite the different methods of data collection (face to face at home for QLSCD; self-report by mailed questionnaire for PELAGIE). The lack of reliability for the opposition and emotionality subscales may explain why we did not find a link between occupational solvent exposure and these behavioral outcomes. Moreover, emotionality items of the internalizing type are more difficult to assess at 2 years of age than externalizing types. Child behavior problems were assessed only by maternal report, and women may be more likely to report problems if they suspect that their occupational solvent exposure was harmful during pregnancy. However, as the study focused on occupational exposures in general (chemical exposures, workload, and use of electrical equipment), we do not believe that this should have influenced the women's assessments of their child's behavior at age two. Attrition at followup is a limitation of this study; nevertheless results remained the same after multiple imputation technique allowed us to take missing values into account. Although exposed women had lower educational levels, were more likely to be single mothers, to smoke cigarettes, or to drink alcohol during pregnancy, the prevalence of these well-known risk factors was low in our population, and the analyses took them into account. In addition, the solvent-aggression behavior association persisted after exclusion of the subgroup of women who were less educated or reported smoking or drinking alcohol during pregnancy. Nevertheless, residual confounding cannot completely be ruled out in this complex field. Furthermore, we cannot rule out the possibility that the associations reported in this study might be due to exposure to other toxicants present in the same occupational environments as solvent exposure.

In conclusion, solvent exposure during pregnancy was associated with nonoptimal child behavior at 2 years of age in this large prospective general-population cohort. These results may be significant in view of the biological plausibility and the dose-response effect we observed. The public health significance of these results may be substantial in view of the high prevalence of maternal occupational solvent exposure around the world. Further largescale epidemiological studies with follow-up at school age are needed to corroborate our results, identify the families of solvents responsible for the behavioral effects, and determine if the associations with externalizing behavior persist. 
TABLE 1 Questions asked of the principal caregiver to assess child behavior

During the last three months, how many times would you say

that your child:

Never Sometimes Often

\section{Attention deficit/Hyperactivity items}

Attention dimension

Was easily distracted, had trouble sticking to any activity?

$\begin{array}{lll}0 & 1 & 2 \\ 0 & 1 & 2 \\ 0 & 1 & 2\end{array}$

Was inattentive?

Hyperactivity-impulsivity dimension

Couldn't sit still, was restless, or hyperactive?

Fidgeted?

$\begin{array}{lll}0 & 1 & 2\end{array}$

Had difficulty awaiting for his/her turn in games?

\begin{tabular}{llll}
\hline Aggression items & & & \\
\hline Got into fights? & 0 & 1 & 2 \\
Physically attacked others? & 0 & 1 & 2 \\
Hit, bit, kicked others? & 0 & 1 & 2 \\
\hline Opposition items & & & \\
\hline Was defiant or refused to comply with adults' request or & 0 & 1 & 2 \\
rules? & 0 & 1 & 2 \\
Didn't seem to feel guilty after misbehaving? & 0 & 1 & 2 \\
Punishment didn't change his/her behavior? & & & \\
\hline Emotionality items & 0 & 1 & 2 \\
\hline Seemed to be unhappy or sad? & 0 & 1 & 2 \\
Was too fearful or anxious? & 0 & 1 & 2 \\
Was worried? & & & \\
& & & 2 \\
\end{tabular}


TABLE 2 Social and demographic characteristics and lifestyle habits of the mother, health status of the child and solvent exposure variables $(n=1278)$

\begin{tabular}{|c|c|c|c|}
\hline Variables & No & $\begin{array}{c}\text { Mean }\left(\mathrm{sd}^{\mathrm{a}}\right) \\
\text { or } \\
\text { percentage }\end{array}$ & $\begin{array}{l}\text { Median [min- } \\
\max ]\end{array}$ \\
\hline Maternal age at first delivery (years) & 1271 & $28.2(3.7)$ & $28.1[16.9-43.3]$ \\
\hline Maternal education $\left(>12\right.$ years) ${ }^{b}$ & 876 & 68.6 & \\
\hline Single mother $(\text { yes })^{\mathrm{b}}$ & 20 & 1.6 & \\
\hline \multicolumn{4}{|l|}{$\begin{array}{l}\text { No. of cigarettes/day at beginning of } \\
\text { pregnancy }\end{array}$} \\
\hline 0 & 951 & 74.9 & \\
\hline 1 to 5 & 118 & 9.3 & \\
\hline$>5$ & 200 & 15.8 & \\
\hline \multicolumn{4}{|l|}{$\begin{array}{l}\text { No. of drinks of alcohol/day at the } \\
\text { beginning of pregnancy }\end{array}$} \\
\hline 0 & 1067 & 84.2 & \\
\hline$<1$ & 174 & 13.7 & \\
\hline$\geq 1$ & 26 & 2.1 & \\
\hline Child's sex (male) ${ }^{b}$ & 655 & 51.3 & \\
\hline Preterm birth (yes) ${ }^{b}$ & 44 & 3.5 & \\
\hline $\begin{array}{l}\text { Small-for-gestational age (birth weight } \\
<5 \text { th percentile) }\end{array}$ & 24 & 1.9 & \\
\hline Breast feeding ( $\leq 3$ months) ${ }^{b}$ & 775 & 63.1 & \\
\hline Child's age at follow-up (months) & 1277 & $26.7(2.2)$ & $26.3[22.4-40.1]$ \\
\hline \multicolumn{4}{|l|}{ No. of siblings at follow-up } \\
\hline 0 & 442 & 34.7 & \\
\hline 1 & 583 & 45.7 & \\
\hline$\geq 2$ & 250 & 19.6 & \\
\hline Mother-child interaction score & 1237 & $19,9(3.4)$ & $20[5-25]$ \\
\hline Father-child interaction score & 1220 & $16,2(4.1)$ & $16[5-25]$ \\
\hline Occupational solvent exposure (exposed) & 650 & 50.8 & \\
\hline
\end{tabular}

${ }^{\mathrm{a}}$ sd: standard deviation,

${ }^{\mathrm{b}}$ Missing data: education, $\mathrm{n}=1$; marital status, $\mathrm{n}=11$; sex, $\mathrm{n}=1$; preterm birth, $\mathrm{n}=45$; small-for-gestational age, $\mathrm{n}=2$; breast feeding, $\mathrm{n}=50$. 
TABLE 3 Behavioral scores correlations $(n=1278)$

\begin{tabular}{lccc}
\hline & \multicolumn{3}{c}{ Correlation coefficient $^{\mathrm{a}}$} \\
\hline Variables & $\begin{array}{c}\text { Attention } \\
\text { deficit/ } \\
\text { hyperactivity }\end{array}$ & Aggression & Opposition \\
\hline Attention & 1.0 & 1.0 & \\
Deficit/Hyperactivity & 0.23 & 0.29 & 1.0 \\
Aggression & 0.45 & 0.04 & 0.14 \\
Opposition & 0.18 & & \\
Emotionality & & &
\end{tabular}

${ }^{\mathrm{a}}$ Spearman coefficient 
TABLE 4 Behavior scores for each exposure group.

\begin{tabular}{lccc}
\hline & No & $\begin{array}{c}\text { Mean } \\
\left(\mathbf{s d}^{\mathrm{a}}\right)\end{array}$ & $\begin{array}{c}\text { Median } \\
{[\mathbf{m i n}-\mathbf{m a x}]}\end{array}$ \\
\hline $\begin{array}{l}\text { Attention deficit/Hyperactivity } \\
\text { score }\end{array}$ & 1235 & & \\
$\quad \begin{array}{l}\text { Solvent exposure } \\
\quad \text { Never exposed }\end{array}$ & 602 & $4,9(2,5)$ & $5[0-12]$ \\
$\quad$ Occasionally exposed & 255 & $5,1(2,4)$ & $5[0-12]$ \\
$\quad$ Regularly exposed & 378 & $5,2(2,6)$ & $5[0-12]$ \\
\hline Aggression score & 1260 & & \\
Solvent exposure & & & \\
$\quad$ Never exposed & 621 & $1,5(1,4)$ & $1[0-6]$ \\
$\quad$ Occasionally exposed & 255 & $1,6(1,4)$ & $2[0-6]$ \\
$\quad$ Regularly exposed & 384 & $1,7(1,5)$ & $2[0-6]$ \\
\hline Opposition score & 1256 & & \\
Solvent exposure & & & \\
$\quad$ Never exposed & 616 & $2,7(1,3)$ & $3[0-6]$ \\
$\quad$ Occasionally exposed & 254 & $2,7(1,3)$ & $3[0-6]$ \\
$\quad$ Regularly exposed & 386 & $2,7(1,3)$ & $3[0-6]$ \\
\hline Emotionality score & 1272 & & \\
Solvent exposure & & & $1[0-5]$ \\
$\quad$ Never exposed & 626 & $1,5(1,2)$ & $1[0-5]$ \\
Occasionally exposed & 258 & $1,4(1,1)$ & $10-5]$ \\
$\quad$ Regularly exposed & 388 & $1,5(1,2)$ & \\
\hline
\end{tabular}

${ }^{a}$ sd: standard deviation. 
TABLE 5 Association between prenatal solvent exposure and child's behavior scores

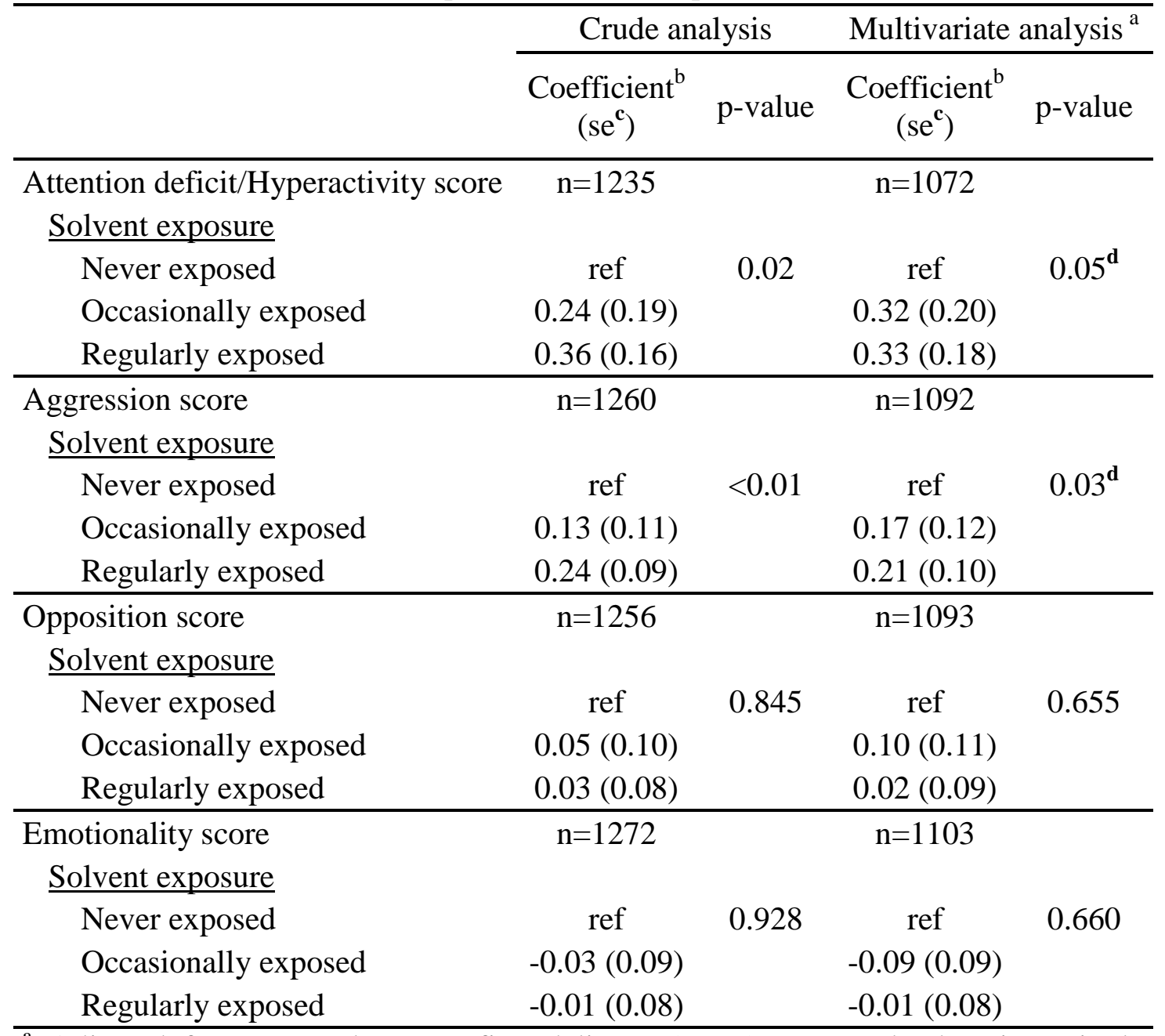

a Adjusted for: maternal age at first delivery (years), maternal education, single mother, number of cigarettes/day at beginning of pregnancy (3 categories), number of drink of alcohol/day at beginning of pregnancy (3 categories), child's sex, preterm birth, small-for-gestational age, breast feeding, number of siblings at follow-up, mother-child interaction, father-child interaction,

${ }^{\mathrm{b}} \beta$ coefficient for linear regression,

${ }^{c}$ se: standard error,

${ }^{\mathrm{d}} \mathrm{p}$ for trend. 
ACKNOWLEDGMENTS: We are grateful to the participants. We thank MA Charles and the EDEN study group for sharing questionnaires, Jean François Viel for his statistical advices, Veronique Villalon for her help, and Jo Ann Cahn for her careful revision of the manuscript.

\section{COMPETING INERESTS: None.}

FUNDING: This research was supported by grants from the National Institute for Public Health Surveillance (InVS), the Ministry of Labor, and the French Agency for Food, Environmental and Occupational Health and Safety (ANSES).

CONTRIBUTORSHIP STATEMENT: Sylvaine Cordier and Luc Multigner designed the study and supervised the overall project. Christine Monfort, Florence Rouget and Ronan Garlantézec were responsible for the field study including questionnaires and medical data. Statistical analyses were conducted by Fabienne Pelé, Gina Muckle, Nathalie Costet and Sylvaine Cordier. Fabienne Pelé wrote the first draft of the manuscript. All authors saw and approved the final manuscript.

LICENCE STATEMENT: The Corresponding Author has the right to grant on behalf of all authors and does grant on behalf of all authors, an exclusive licence (or non-exclusive for government employees) on a worldwide basis to the BMJ Publishing Group Ltd and its Licensees to permit this article (if accepted) to be published in Occupational and Environmental Medicine and any other BMJPGL products to exploit all subsidiary rights, as set out in our licence (http://group.bmj.com/products/journals/instructions-forauthors/licence-forms ) and the Corresponding Author accepts and understands that any supply made under these terms is made by BMJPGL to the Corresponding Author. 


\section{REFERENCES}

1. White RF, Proctor SP. Solvents and neurotoxicity. Lancet. 1997;349(9060):1239-1243

2. Adinolfi M. The development of the human blood-CSF-brain barrier. Dev Med Child Neurol. 1985;27(4):532-537.

3. Grandjean P, Landrigan PJ. Developmental neurotoxicity of industrial chemicals. Lancet. 2006;368(9553):2167-2178.

4. Rice D, Barone S, Jr. Critical periods of vulnerability for the developing nervous system: evidence from humans and animal models. Environ Health Perspect. 2000;108 Suppl 3:511-533.

5. Julvez J, Grandjean P. Neurodevelopmental toxicity risks due to occupational exposure to industrial chemicals during pregnancy. Ind Health. 2009;47(5):459-468.

6. Multigner L, Catala M, Cordier S, et al. The INSERM expert review on Glycol Ethers: findings and recommandations. Toxicol Lett. 2005; 156:29-37.

7. Nelson BK, Brightwell WS, Setzer JV, et al. Ethoxyethanol behavioral teratology in rats. Neurotoxicology. 1981;2(2):231-249.

8. Nelson BK, Brightwell WS. Behavioral teratology of ethylene glycol monomethyl and monoethyl ethers. Environ Health Perspect. 1984;57:43-46.

9. Eskenazi B, Gaylord L, Bracken MB, et al. In utero exposure to organic solvents and human neurodevelopment. Dev Med Child Neurol. 1988;30(4):492-501.

10. Till C, Koren G, Rovet JF. Prenatal exposure to organic solvents and child neurobehavioral performance. Neurotoxicol Teratol. 2001;23(3):235-245.

11. Laslo-Baker D, Barrera M, Knittel-Keren D, et al. Child neurodevelopmental outcome and maternal occupational exposure to solvents. Arch Pediatr Adolesc Med. 2004;158(10):956-961.

12. Guldner L, Monfort C, Rouget F, et al. Maternal fish and shellfish intake and pregnancy outcomes: a prospective cohort study in Brittany, France. Environ Health. 2007;6:33-40.

13. Garlantezec R, Monfort C, Rouget F, et al. Maternal occupational exposure to solvents and congenital malformations: a prospective study in the general population. Occup Environ Med. 2009;66(7):456-463.

14. Garlantézec R, Multigner L, Labat L, et al. Urinary biomarkers of exposure to glycol ethers and chlorinated solvents during pregnancy: determinants of exposure and comparison with indirect methods of exposure assessment. Occup Environ Med. 2012;69(1):62-70.

15. Quebec Longitudinal Study of Child Development (QLSCD).

http://www.iamillbe.stat.gouv.qc.ca/default_an.htm

Accessed Novembre 10, 2011

16. Quebec Longitudinal Study of Child Development (QLSCD). Survey description and Methodology.

http://www.iamillbe.stat.gouv.qc.ca/bebe/bebe_v2no1_an.htm

Accessed November 10,2011

17. Boyle MH, Offord DR, Hofmann HG, et al. Ontario Child Health Study. I. Methodology. Arch Gen Psychiatry. 1987;44(9):826-831.

18. Achenbach TM, Edelbrock C, Howell CT. Empirically based assessment of the behavioral/emotional problems of 2- and 3- year-old children. J Abnorm Child Psychol. 1987;15(4):629-50.

19. Tremblay R, Vitaro F, Gagnon C. A prosocial scale for the preschool behaviour questionnaire : concurrent and predistive correlates. International journal of behavioral development. 1992;15(2):227-245. 
20. Huijbregts SC, Seguin JR, Zoccolillo M, et al. Associations of maternal prenatal smoking with early childhood physical aggression, hyperactivity-impulsivity, and their cooccurrence. J Abnorm Child Psychol. 2007;35(2):203-215.

21. Romano E, Tremblay RE, Farhat A, et al. Development and prediction of hyperactive symptoms from 2 to 7 years in a population-based sample. Pediatrics. 2006;117(6):21012110.

22. Tremblay RE, Nagin SD, Seguin JR, et al. Physical aggression during early childhood: trajectories and predictors. Pediatrics. 2004; 114:e43-e50.

23. Petitclerc A, Boivin M, Dionne G, et al. Disregard for rules: the early development and predictors of a specific dimension of disruptive behavior disorders. J Child Psychol Psychiatry. 2009; 50(12):1477-1484.

24. Boyle MH, Offord DR, Racine Y, et al. Evaluation of the original Ontario Child Health Study scales. Can J Psychiatry. 1993; 38:397-405.

25. Lubke GH, Hudziak JJ, Derks EM, et al. Maternal ratings of attention problems in ADHD: evidence for the existence of a continuum. J. Am. Acad. Child. Psy. 2009 48: 10851093.

26. Mamelle N, Munoz F, Grandjean H. Fetal growth from the AUDIPOG study. Establishment of reference curves [in French]. J Gynecol Obstet Biol Reprod. 1996; 25(1):6170 .

27. Clayton D, Hills M. Statistical models in epidemiology. 4th ed. New York: Oxford university press; 1996.

28. Buhi ER, Goodson P, Neiland TB. Out of sight, not out of mind: strategies for handling missing data. Am J Health Behav. 2008; 32:83-92.

29. Rubin DB. Multiple Imputation for Nonresponse in Surveys. New York: Wiley; 1987. 24, 2011. (DOI:10.1136/oem.2010.062315).

30. Rydell AM. Family factors and children's disruptive behaviour: an investigation of links between demographic characteristics, negative life events and symptoms of ODD and ADHD. Soc Psychiatry Psychiatr Epidemiol. 2010;45(2):233-244.

31. Linnet KM, Obel C, Bonde E, et al. Cigarette smoking during pregnancy and hyperactive-distractible preschooler's: a follow-up study. Acta Paediatr. 2006;95(6):694-700.

32. Rodriguez A, Olsen J, Kotimaa AJ, et al. Is prenatal alcohol exposure related to inattention and hyperactivity symptoms in children? Disentangling the effects of social adversity. J Child Psychol Psychiatry. 2009;50(9):1073-1083.

33. Galéra C, Cote SM, Bouvard MP et al. Early risk factors for hyperactivity-impulsivity and inattention trajectories from age 17 months to 8 years. Arch Gen Psychiatry. 2011; 68(12):1267-1275.

34. Petitclerc A, Tremblay RE. Childhood disruptive behaviour disorders: review of their origin, development, and prevention. Can J Psychiatry. 2009;54(4):222-231.

35. Cote SM, Boivin M, Liu X, et al. Depression and anxiety symptoms: onset, developmental course and risk factors during early childhood. J Child Psychol Psychiatry. 2009;50(10):1201-1208.

36. Robinson M, Oddy WH, Li J, et al. Pre- and postnatal influences on preschool mental health: a large-scale cohort study. J Child Psychol Psychiatry. 2008;49(10):1118-1128.

37. Delclos GL, Gimeno D, Arif AA, et al. Occupational risk factors and asthma among health care professionals. Am J Respir Crit Care Med. 2007;175:667-75.

38. Charles LE, Loomis D, Demissie Z. Occupational hazards experienced by cleaning workers and janitors: a review of the epidemiologic literature. Work 2009;34:105-16.

39. Rylander L, Kallen B. Reproductive outcomes among hairdressers. Scand J Work Environ Health 2005;31:212-7. 
40. Wennborg H, Magnusson LL, Bonde JP, et al. Congenital malformations related to maternal exposure to specific agents in biomedical research laboratories. J Occup Environ Med 2005;47:11-9. 